\title{
EL DERECHO AL OLVIDO DIGITAL. LA NUEVA CARA DE UN DERECHO TAN VIEJO COMO POLÉMICO
}

\section{THE RIGHT TO DIGITAL FORGET. THE NEW FACE OF A RIGHT AS OLD AS POLEMIC}

RESUMEN:

El presente artículo tiene como objetivo analizar el derecho al olvido en la acción de habeas data, conforme las reglas que justifican su reconocimiento, y los requisitos para establecer cuándo una persona se encuentra amparada por el derecho al olvido. Posteriormente se hará un reconto de la evolución del derecho al olvido en Europa y su recepción en Latinoamérica, para arribar finalmente a conclusiones sobre el debate actual doctrinario, legal y jurisprudencial de la existencia y extensión del derecho al olvido, en cualquiera de sus versiones.

\begin{abstract}
This article aims to analyze the right to be forgotten in the action of habeas data, according to the rules that justify its recognition, and the requirements to establish when a person is protected by the right to be forgotten.

Subsequently there will be a recount of the evolution of the right to forget in Europe and its reception in Latin America, to finally arrive at conclusions on the current doctrinal, legal and jurisprudential debate about the existence and extension of the right to forget, in any of its versions
\end{abstract}

PALABRAS CLAVE: Habeas Data - Constitución Nacional - Derecho al olvido - Derecho comparado - Ley 25326.

KEY WORDS: Habeas Data - National Constitution - Law to oblivion - Comparative law - Law 25326

\section{Introducción: El tiempo, la memoria y el derecho al olvido}

El debate sobre el denominado derecho "al olvido" o "a ser olvidado" parte de las no-

1 Abogado, Doctor en Derecho Universidad Nacional de Buenos Aires, Profesor Adjunto de Derecho Constitucional I ("Derecho Constitucional del Poder") y Derecho Constitucional II ("Derecho Constitucional de la Libertad" -incluye Derechos Humanos y Derecho Procesal Constitucional-), en la Facultad de Derecho de la Universidad Nacional de Rosario, Profesor de Adjunto a cargo de cátedra, Derecho Procesal Constitucional y Trasnacional en la Facultad de Derecho de la Universidad Nacional de Rosario, y Juez de la Sala Segunda de la Cámara de Apelación en lo Civil y Comercial de Rosario.. 
ciones del tiempo y la memoria y se vincula derechamente con los hechos pasados-esto porque más allá de que ciertos hechos que puedan ser registrados refieran a momentos recientes y mantengan actualidad porque están desarrollándose o de que pueda especularse con hechos futuros, los sistemas de información sólo recopilan hechos pertenecientes al pasado-, donde en la dimensión humana -a diferencia de lo que ocurre en el ámbito informático-, el flujo del tiempo va paralela y gradualmente desdibujando los hechos percibidos y agotando su relevancia social o su potencial informativo hasta el punto en que muchos de ellos ya no merecen ser colectivamente memorados.

La cuestión no es del todo nueva, pues entre los diversos pensadores del mundo antiguo que se ocuparon de esta temática, Aristóteles aludía a la exclusiva ligazón entre memoria y pasado, puntualizando que ni los hechos presentes ni los futuros se vinculan con la memoria, ya que ésta se manifiesta dentro de la imaginación de quien tiene la capacidad de recuperación mental de una percepción pasada ${ }^{2}$, y Homero postulaba cierta indulgencia respecto de hechos negativos acontecidos algún tiempo atrás a través de su célebre frase "Dejemos que el pasado sea el pasado"

Desde el plano jurídico, situados concretamente en el ámbito del derecho a la información, la cuestión del reconocimiento del derecho al olvido tiene sus bemoles pues coexisten distintos valores y principios que son típicos de algunas de sus especialidades (derecho de prensa, derecho de la protección de datos, derecho de acceso a la información, etc.), que en algunos casos se presentan, prima facie, como antagónicos pues por ejemplo, tanto en el plano de la libertad de expresión como en el del derecho de acceso a la información pública -presupuestos básicos de la libertad de prensa-rige el principio de máxima publicidad, mientras que en el ámbito del derecho a la protección de los datos personales resulta de aplicación el principio de minimización de los datos. En esta dualidad de principios contrapuestos se inserta el denominado "derecho al olvido", "derecho a ser olvidado" o right to be forgotten (RTBF), que cuenta con antecedentes específicos en todas esas disciplinas.

Así, en el campo de las normas que regulan el derecho a la protección de los datos personales se lo ha reconocido, en las primeras generaciones de leyes de este tipo, con alcance limitado a los datos negativos de solvencia patrimonial y de crédito, y sólo más recientemente ha sido extendido a otras informaciones negativas, partiendo de diversos antecedentes verificados durante el siglo pasado respecto de informaciones publicadas en los más diversos medios de expresión (películas, documentales, carteles en la vía pública, programas de radio y de televisión).

Estos nuevos alcances del antiguo derecho al olvido, en definitiva pretenden atender aciertos efectos negativos del uso de ciertas TICsen el ámbito de Internet, para lo cual se lo ha reconstruido con tales nuevos alcances a partir de los principios generales que regulan los tratamientos (v.gr., calidad de los datos, consentimiento del interesado, seguridad de la información, minimización de los datos) y de los tradicionales derechos reconocidos a los titulares de los datos (acceso, rectificación, cancelación, actualización, oposición al tratamiento, etc.), generándose, así,lo que actualmente se ha denominado "derecho al olvido 2.0" (RTBF 2.0), que opera en medios digitales, sobre información cierta, lícitamente publicada, que por su antigüedad y carácter negativo afecta desproporcionada e injustamente a quien es objeto de la información publicada.

\footnotetext{
2 ARISTÓTELES (1995): Acerca de la memoria (“On memory”), en “The complete Works of Aristotle”, Jonathan Aristóteles Barnes (editor), Princeton University Press, 1995, págs. 714/720.

3 http://www.proverbia.net/citasautor.asp?autor=1415.
} 


\section{Reglas que justifican su reconocimiento.}

Entre los derechos que se reconocen a los titulares de los datos en las normas que regulan el derecho a la protección de los datos personales (usualmente denominados "derechos ARCO"), los que se vinculan directamente con el derecho al olvido son tres: el de acceso a los datos, el de cancelación de los datos y el de oposición al tratamiento de los datos.

Algunos autores (e incluso la versión de 2012 del actual Reglamento General de Protección de Datos de la Unión Europea) ubican al derecho al olvido exclusivamente dentro del derecho de cancelación respecto de datospersonales vetustos (los que ya no cumplen con la finalidad para la cual fueron recabadosdado que ofrecen un perfil desactualizado de la persona a la que refieren). Esta perspectiva no es del todo correcta porque por más que siempre hay algo que se suprime (por ejemplo, un vínculo) también puede ser visualizado como una excepción al derecho de acceso a datos que no deben ser cancelados o puede ejercerse a fin de que el titular de los datos impida, vía oposición, que un dato sea objeto de determinados tratamientos, en ambos casos, sin que ello necesariamente implique su cancelación.

Por ello, aparece más propio vincularlo derechamente con el principio de calidad de los datos, que, por ejemplo está contenido, en el caso argentino, en el art. 4ํinc. 1ㅇ de la ley 25.326 (de protección de los datos personales y hábeas data), que establece: "Los datos personales que se recojan a los efectos de su tratamiento deben ser ciertos, adecuados, pertinentes y no excesivos en relación al ámbito y finalidad para los que se hubieren obtenido" y que también prevé en el mismo artículo pero en su inc. 70: "Los datos deben ser destruidos cuando hayan dejado de ser necesarios o pertinentes a los fines para los cuales hubiesen sido recolectados". Como consecuencia de ello, si un dato no reúne los requisitos establecidos en la primera norma, quedan habilitadas diversas facultades que también están establecidas en la ley (actualización, rectificación, eliminación, bloqueo, etc.), que incluyen la eliminación del dato de la base de datos, tal como lo indica la segunda norma recién citada.

A tenor de estas reglas -comunes en todas las leyes de protección de datos-, todo dato excesivo, inadecuado, impertinente o que haya perdido utilidad por el mero transcurso del tiempo debe ser eliminado o sujetarse a un tratamiento limitado ( $y$ aquí entra entonces el derecho a la oposición a determinados tratamientos), y en caso que por alguna razón legal deba ser mantenido, quien solicita el acceso debe contar con un interés legítimo en acceder a esa información (por ejemplo, la administración tributaria, para determinar un incremento patrimonial sospechoso de un contribuyente, o un pariente de una persona fallecida para indagar sobre datos de salud específicos de su ancestro para proveer al tratamiento de una enfermedad grave que lo afecta).

En este contexto aparece la necesidad de dotar de alguna herramienta legal que permita solucionar la situación, muchas veces injusta, por la que atraviesaquien aparece vinculado actualmente a una información antigua y negativa sobre su persona y que lo transforma, en los hechos, en prisionero de su pasado.

Esa herramienta, precisamente, es el denominado "derecho al olvido" respecto de aquellas informaciones que alguna vez fueron actuales y que se publicaron lícitamente, pero que con el transcurrir del tiempo perdieron vigencia y actualmente causan un daño desproporcionado con su publicación, razón por la cual ameritan ser objeto de un tratamiento limitado o derechamente eliminadas. Juegan aquí las nociones de tiempo, memoria, perdón, rehabilitación, desarrollo de la personalidad y plan de vida.

Es que, como lo indica Peyrano: "Lo "público" del dato debe ponderar un cierto grado de relatividad, de modo tal que sea posible para la persona, un cierto control sobre las 
informaciones a su respecto, de modo tal de adecuar su 'perfil' actual, o, eventualmente, permitirle una cierta 'reconstrucción' de aspectos de su vida, a fin de que no quede atada para siempre a los condicionamientos de su pasado.

"Olvidar es humano, y como la técnica debe ser para el hombre, y no el hombre para ella -como una suerte de esclavo de la misma-, la técnica debe contemplar o admitir-para satisfacer los intereses humanos- que cuando se encuentra justificado y no se vean comprometidos intereses públicos o colectivos, el 'olvido' impida que ciertos datos personales que fueron 'públicos', recobren la 'publicidad' que les da el recuerdo."

En definitiva, y como lo ha expresado desde su constitución la Corte Constitucional colombiana: "Los datos tienen por su naturaleza misma una vigencia limitada en el tiempo la cual impone a los responsables o administradores de bancos de datos la obligación ineludible de una permanente actualización a fin de no poner en circulación perfiles de 'personas virtuales' que afecten negativamente a sus titulares, vale decir, a las personas reales. De otra parte, es bien sabido que las sanciones o informaciones negativas acerca de una persona no tienen vocación de perennidad y, en consecuencia, después de algún tiempo tales personas son titulares de un verdadero derecho al olvido"s.

El reconocimiento de un derecho al olvido (o a ser olvidado) busca, entonces. reconocer que, pese a que no es posible para cualquier persona borrar el recuerdo o rehacer sus decisiones pasadas, sí lo es contar con un derecho que la sustraiga de revivir esos acontecimientos que le generan una huella traumática, de acoso o desagrado.

Ahora bien: conceptualmente, los términos "derecho al olvido" o "derecho a olvidar el pasado" o "derecho al olvido" no resultan totalmente apropiados y pareciera técnicamente más correcto aludir a un "derecho a no recordar obligatoriamente" porque las reclamaciones basadas en éste pretenden evitar que los afectados revivan pública e indefinidamente ciertas experiencias negativas del pasado.

Lo interesante de este derecho radica en que corre sobre dos carriles que van en sentido contrario, desde que mientras debe existir una expansión progresiva de las posibilidades de expresión personal en un entorno público participativo y democrático (lo que implica una exaltación progresiva de los valores inherentes a la libertad de expresión, creencias, expresión del pensamiento, etc.), por otra parte aparecen cada vez más herramientas de protección contra la exposición excesiva y no deseada de los individuos en el escrutinio colectivo. Y estas tensiones, en definitiva, se centran casi antagónicamente, por un lado, en la búsqueda de un marco más amplio de ejercicio de la libertad de actuar sin opresión, y por el otro, en la necesidad de una nueva formulación de mecanismos de protección de los derechos fundamentales frente a la invasión de ciertas esferas intocables de cada persona en particular, en la idea de restaurar el equilibrio que debe existir entre libertades y derechos.

En este campo la intervención de los adelantos de las TICs es evidente, porque la natural preocupación por la reedición de momentos pasados se agiganta cuando tales progresos proponen nuevos medios de exposición pública, tal como lo destacaran Warren y Brandeisen aquél lejano 1890 frente a la aparición del telégrafo, la fotografía y la prensa rotativa, al sentar las bases del derecho a la privacidad, partiendo de las ideas expuestas por Cooley respecto de la existencia de un derecho a ser dejado solo o a no ser molestado ("theright to be letalone")'.

4 PEYRANO, Guillermo (2004): "El tratamiento de datos personales extraídos de informaciones periodísticas, y su acceso a través de Internet. La protección de los datos personales y el derecho a la autodeterminación informativa, ante las nuevas formas de procesar y comunicar la información”, en Estudios de Derecho - Estudios de Derecho Privado - Estudios de Derecho Público - Derecho Público y Procesal" (Homenaje a la Facultad de Derecho de la Universidad Católica Andrés Bello en su 50 aniversario), Editorial Universidad Católica Andrés Bello, Caracas (Venezuela), 2004..

5 Corte Constitucional de Colombia, Sentencia T-414/92, disponible en http://www.corteconstitucional.gov.co/relatoria/1992/t-414-92.htm.

6 WARREN, Samuel - BRANDEIS, Louis (1890): “The Right to Privacy”, Harvard Law Review, vol. IV, núm. 5, 15/12/1890. 
Esta más que centenaria definición de la privacidad como una suerte de "derecho a ser dejado en paz", en especial por los medios de comunicación, presenta una clara simetría con el "derecho al olvido" en la actualidad, donde la discusión más relevante se centra en su inserción en el contexto de las TICs,caracterizadas por fenómenos desconocidos pocas décadas atrás, como los datos masivos (big data), la computación en la nube (cloudcomputing), la internet de las cosas (IOT), el uso de algoritmosy de la inteligencia artificial (A.I.), que configuran un estado de cosas donde no sólo hay hiperinformación sino también una hiperdesprotección de las personas que si bien se manifiesta de muchas maneras, en especial se provoca por consecuencia del uso generalizado de las herramientas que nos auxilian en la web a buscar la información personal, esto es, principalmente los motores de búsqueda de Internet (los buscadores).

Es que en una web que ya no olvida por la infinidad de nuevos recursos que permiten el almacenamiento casi ilimitado y la instantánea recuperación de la información en ella alojada, cualquier información personal, aunque refiera a hechos ocurridos mucho tiempo atrás, recobra actualidad en un listado de resultados -que precisamente ubica en los primeros lugares los sitios más visitados, que generalmente son los que contienen información que puede resultar perjudicial-, castigando injustamente a quienes se refieren esas informaciones negativas, respecto de quienes ya no presentan un perfil actualizado.

Este contexto reclama, entonces, dotar a la persona perjudicada por la publicación injustificada de información obsoleta de cierta posibilidad de control,pero no sólo frente a los sistemas de información del sector privado (donde los gigantes tecnológicos ponen a disposición los buscadores más eficientes), sino también respecto de los del ámbito público, tal como lo expusiera Orwell en forma de novela en su "1984" con su frase "Quien controla el pasado controla el futuro. Quien controla el presente controla el pasado", remarcando que el control del pasado es una herramienta típica de los Estados totalitarios.

Por ello, dentro de una serie de nuevos derechos que se han ido incorporando gradualmente (v.gr., los derechos a la privacidad desde el diseño y a la privacidad por defecto; el derecho a la portabilidad de los datos, etc.), tanto la doctrina, como la jurisprudencia e incluso decisiones de no pocos órganos de control específicos de las leyes de protección de datos (institutos, comisiones, agencias y direcciones de protección de datos personales) vienen reconociendo, no sin límites, este derecho a fin de coadyuvar a que los afectados por esas noticias vetustas puedan superar sus errores del pasado y seguir con sus vidas, en lo que se conoce como el "rightto moveon".

En definitiva, el reconocimiento de este derecho a ser olvidado parte de las siguientes premisas: a) el devenir de los hechos en el tiempo afecta exclusivamente a los seres humanos por ser los únicos capaces de evaluar su trayectoria y sufrir los efectos de lo que hacen; b) el paso del tiempo en su dimensión psicológica es relevante sólo en el momento presente (porque ni el pasado ni el futuro se conocen exactamente), pero el pasado afecta al individuo en su proyección actual, en la medida en que se manifiesta como causa de efectos actuales; c) la capacidad de memoria de los seres humanos se limita a los acontecimientos del pasado que se reproducen en las imágenes mentales del individuo; y d) la memoria o la reminiscencia del pasado no representa la actividad mental neutral o pasiva, ya que tales experiencias internas fuerzan al individuo a revivir los restos del pasado:.

7 George Orwell, 1984, en https://espanol.free-ebooks.net/ebook/1984/pdf.

8 GHEZZI, Alessia (2014): Theethics of memory in a digital age, Palgrave Mac Millan, Reino Unido, 2014, cit. en O direitoaoesquecimento na Europa e no Brasil, en Revista de Derecho, Comunicaciones y Nuevas Tecnologías No. 15, Universidad de los Andes, Colombia, 2016, en prensa. 
Como lo indica Peyrano, en el contexto tecnológico actual donde la información circula mayormente por Internet, la técnica directamente ha barrido con la característica típica del olvido humano ya que "esas informaciones 'recordadas' de un modo casi instantáneo, renuevan su condición de datos públicos por el acceso irrestricto que admiten los sitios 'web' bajo examen, y sus titulares no pueden saber quiénes, qué, cuándo y con qué motivos están sabiendo algo sobre ellos.

"Es decir que el referido acceso irrestricto a las informaciones que han sido del dominio público 'retroalimenta' la publicidad de los datos personales que constan o pueden ser extraídos de las mismas.

"Se genera de tal modo un circuito que impide no sólo el humano olvido, sino que también expande el 'recuerdo', colocando esos datos al alcance de cualquier interesado, sin prácticamente ningún esfuerzo.

"Sustrae del control de los titulares de esos datos, la posibilidad de ejercer cualquier potestad de control".9

Por ello, la efectiva vigencia de los derechos en este ámbito requiere no sólo del reconocimiento de facultades específicas que puedan ser ejercidas por los titulares de los datos, sino también de una posición proactiva de quienes tratan esos datos, que deben contar con mecanismos para que se proceda, luego de cierto tiempo, a la eliminación automática de datos vetustos, pues tal como lo propone Mayer-Schönberger, el derecho a ser olvidado no debe ser asociado únicamente con la intención de los afectados por los datos de eliminar información de los registros accesibles al público sino que también debe alcanzar, especialmente en la era digital, a mecanismos automáticos que incluyan el almacenamiento de datos con fechas de caducidad que de manera programada activen la supresión de la información al transcurrir un determinado período de tiempo ${ }^{10}$.

\section{Requisitos (tentativos) para establecer cuándo una persona se encuentra ampara- da por el derecho al olvido.}

A partir de los diversos antecedentes revistados, la doctrina ha establecido que para que se configure una situación que se encuentre amparada por el derecho al olvido, deben confluir los siguientes criterios:

1. La existencia de un dato vetusto que cause un efecto dañino, persecutorio o denigrante. Esto porque debe detectarse algún daño real o potencial causado injustamente por la exposición temporalmente excesiva de un evento en el que la persona ha participado o tuvo alguna relación directa. No basta la argumentación de simples intereses individuales que impliquen un mero deseo donde no se demuestre la existencia de efectos nocivos, causados abusivamente en detrimento de la persona, porque este derecho no está pensado para afectar arbitrariamente el libre flujo de información que debe existir en toda sociedad democrática.

\section{El transcurso de un tiempo razonable (no contemporaneidad).}

El evento o contexto fáctico objeto del ejercicio de este derecho no debe ser actual o contemporáneo, porque en la esencia del derecho al olvido se encuentra el juego entre

9 PEYRANO, Guillermo (2004): "El tratamiento de datos personales extraídos de informaciones periodísticas, y su acceso a través de Internet. La protección de los datos personales y el derecho a la autodeterminación informativa, ante las nuevas formas de procesar y comunicar la información”, en Estudios de Derecho - Estudios de Derecho Privado - Estudios de Derecho Público - Derecho Público y Procesal" (Homenaje a la Facultad de Derecho de la Universidad Católica Andrés Bello en su 50 aniversario), Editorial Universidad Católica Andrés Bello, Caracas (Venezuela).

10 MAYER SCHÖNBERGER, Viktor (2009): “Delete: the virtue of forgetting in the digital age”, Princeton University Press, pág. 171. 
el tiempo y la memoria, que es esencial para determinar lo que puede ser olvidado y lo que es digno de ser recordado. Es que -salvo algún caso excepcional- tanto los hechos que se manifiestan en el presente como los sucedidos en el pasado reciente no han sufrido un período de maduración que permita evaluar su relevancia pública actual o potencial, a fin de definir si gozan o no de un carácter histórico y si pueden darse por agotadas las funciones informativas.

\section{La ausencia de historicidad.}

La huella histórica que un suceso pasado puede tener es un factor determinante en la evaluación de la legitimidad de la pretensión de pasar al olvido ciertos hechos, ya que los hechos históricos, debido a su relevancia social constante en el tiempo, trascienden los intereses individuales y su disponibilidad se torna derechamente en un derecho colectivo que impide que juegue el interés individual en que resulten olvidados, aun cuando fueran altamente dolorosos para la persona afectada o para sus parientes y descendientes y haya transcurrido un largo tiempo desde la fecha de su ocurrencia, pues se hace relevante su transmisión a todas las generaciones futuras, con independencia del malestar individual o colectivo que pueda provocar.

Este requisito es el más casuístico, puesto que es imposible definir a priori lo que tiene y lo que no tiene importancia histórica y su determinación es siempre el resultado de una prologada construcción intelectual y cultural en el tiempo, que proviene de la discusión pública, del debate en ciertos círculos cerrados, de la participación de académicos, periodistas, testigos, órganos del Estado y diversos sectores sociales.

\section{El agotamiento de la relevancia informativa del evento o el alcance de la rehabilitación o el perdón en materia penal}

Este recaudo lleva a evaluar si los hechos que se pretenden eliminar alcanzaron un determinado punto de saturación en su exposición pública, porque cualquier exposición adicional de tales hechos perjudiciales debe considerarse excesiva, desproporcionada o injusta. A través de este criterio se introduce un marco de análisis cualitativo, dentro del cual se debe justificar la decisión de mantener la información a disposición de la comunidad, de modo que pueden pasar al olvido los hechos deshonrosos que no sean contemporáneos, carezcan de cualquier elemento de la historicidad o hayan llegado al tramo final de su relevancia pública, sin que queden residuos informativos que superen a las noticias contemporáneas.

Así, el derecho a ser olvidado tiene campo fértil para su aplicación en el área de los informes comerciales y en el de las condenas penales, situación donde cabe evaluar si los hechos pasados han ejercido plenamente su función informativa de la sociedad y si las sanciones impuestas al delincuente han alcanzado sus objetivos típicos, esto es, la rehabilitación o recuperación, que incluye el restablecimiento de la autoestima de la víctima. La publicidad y la amplia difusión de información sobre los actos ilegales se muestra como necesaria e indispensable para la restauración de los derechos de las víctimas (que tiene tanto una función de catarsis social, como también una educativa de la ciudadanía respecto del sentido de la justicia y el respeto de los demás), pero la reparación a través de la publicidad sobre el evento ilícito pasado no puede durar para siempre, porque debe atenderse también a la función social de la pena que debe también tender a recomponer, luego de transcurrido su término, la estimación pública, y otorgarle al condenado la posibilidad de recuperar su autoestima, reconciliarse con la sociedad y contar con una nueva oportunidad de rehacer su vida, porque de lo contrario se configuraría una especie de perpetuo castigo que es tanto aberrante como ilegal. 


\section{La evolución del derecho al olvido en Europa y su recepción en Latinoamérica.}

Sin perjuicio de la existencia de diversos antecedentes jurisprudenciales habidos en suelo estadounidense", este "derecho a ser olvidado" encuentra arraigo en el ámbito europeo, incluso desde la era preinformática, donde se destaca el caso "Lebach", resuelto por el Tribunal Constitucional Federal Alemán respecto de un documental que había preparado un canal de televisión respecto de un hecho ocurrido en 1969 cuando cuatro soldados que custodiaban un depósito de municiones fueron asesinados mientras dormían. El Tribunal hizo lugar a la pretensión de uno de los condenados por este crimen que estaba a punto de salir de la prisión y que se oponía a la difusión televisiva de ese documental, entendiendo que tal reproducción lo estaría obligando a revivir tiempos pasados, y más específicamente hechos de su vida que eran un verdadero fastidio para él, y que ya resultaban irrelevantes para la sociedad. Se admitió así la pretensión del todavía recluso y se consideró además especialmente que, en la tensión entre el derecho fundamental a la protección de la personalidad (más específicamente la privacidad y la intimidad) y el derecho fundamental a la libertad de información, debía prevalecer el primero, porque con la reproducción televisiva de información sin ningún tipo de relevancia actual se pondría en riesgo la posibilidad de la rehabilitación del actor.

Esta solución se entroncaría luego con un célebre caso referido a la ley de censo de la población, fallado en 1983 por el mismo tribunal, por el cual reconoció la existencia de un nuevo derecho fundamental "a la autodeterminación informativa", derivado de la dignidad humana, que autorizaba a cuestionar la recolección injustificada de cierta información privada, con afección potencial al libre desarrollo individual. La sentencia anuló, por inconstitucionales, tres preceptos de la ley del Censo de Población de 1983, entre ellos los relativos al cotejo de los datos personales del censo estatal con los de los padrones y estableció que el derecho al libre desarrollo de la personalidad abarca "la facultad del Individuo de decidir básicamente por sí mismo cuándo y dentro de qué límites procede revelar situaciones referentes a la propia vida", aunque este derecho "a la autodeterminación informativa" es limitable "en aras del interés preponderante de la colectividad", teniendo en cuanta la necesidad de protección especial cuando se trata de datos acumulados automáticamente, en los que lo decisivo no es tanto la clase de datos como "la posibilidad de utilización de los mismos"12.

En el plano comunitario, el derecho a ser olvidado empieza lentamente a configurarse a partir de los principios establecidos en el Convenio 108 de 1981 "para la protección de las personas con respecto al tratamiento automatizado de datos de carácter personal"; de las reformas legislativas que consecuentemente realizaron la mayoría de los países europeos (v.gr., las de 1990 a la ley de protección de datos alemana de 1977); dela Directiva comunitaria 95/46, aprobada en 1995 por el Parlamento Europeo y el Consejo "relativa a la protección de las personas físicas en lo que respecta al tratamiento de datos personales y a la libre circulación de estos datos" y también de las subsecuentes normas de transposición nacionales (por ejemplo, la reforma de 1999 a la ley española de protección de datos de 1992).

Tales normas, pese a no reconocer expresamente este derecho general a ser olvidado, establecen principios generales y dotan a los titulares de los datos de derechos específicos que son suficientes para su construcción, incluso por extensión del limitado

11 Se destacan diversos antecedentes principalmente dictados en California, a partir de un célebre fallado por la Corte de Apelaciones de ese Estado estableció que el uso del nombre real de la protagonista que había sido trabajadora sexual en Nueva Orleans en un film ("The Red Kimono") afectaba su derecho a la felicidad (que incluye el de estar libre de ataques innecesarios al carácter, posición social o reputación),y por lo tanto tenía un derecho a que no se informara sobre hechos pasados que deseaba olvidar y que la afectaban gravemente en su vida actual (Melvin v. Reid, 112 Cal.App. 285, 297 P. 91, 1931). 12 Sentencia BVerfGE 65, 1 [Censo de Población]. 
reconocimiento habido respecto de los datos de solvencia patrimonial tratados por los burós de crédito, caso donde el legislador, al reconocer tal derecho al olvido, realizó una labor de ponderación de los derechos en juego (el del titular del dato, a poder acceder nuevamente al crédito luego de determinado tiempo, por un lado, y por el otro, el de los acreedores, a lograr la satisfacción de su acreencia y el general de la tutela del crédito frente a quienes incumplen o cumplen tardíamente con sus obligaciones).

Normas de este tipo son comunes en el derecho comparado y se ubican dentro de las leyes generales de protección de datos (caso argentino); en leyes sectoriales respecto de los servicios e información crediticia (caso peruano) e incluso en códigos de defensa del consumidor (caso brasileño).

Así, v.gr., la ley argentina $n^{\circ} 25.326$ (de similar manera que el art. 43, párrafo 1, del Código de Defensa del Consumidor brasileño), establece en su art. 26, ap. 4: "Sólo se podrán archivar, registrar o ceder los datos personales que sean significativos para evaluar la solvencia económico-financiera de los afectados durante los últimos cinco años. Dicho plazo se reducirá a dos años cuando el deudor cancele o de otro modo extinga la obligación, debiéndose hace constar dicho hecho", y su decreto reglamentario, 1558/01 dispone a este respecto: "Para apreciar la solvencia económico-financiera de una persona, conforme lo establecido en el artículo 26, inciso 4, de la Ley № 25.326, se tendrá en cuenta toda la información disponible desde el nacimiento de cada obligación hasta su extinción. En el cómputo de CINCO (5) años, éstos se contarán a partir de la fecha de la última información adversa archivada que revele que dicha deuda era exigible. Si el deudor acredita que la última información disponible coincide con la extinción de la deuda, el plazo se reducirá a DOS (2) años. Para los datos de cumplimiento sin mora no operará plazo alguno para la eliminación. A los efectos del cálculo del plazo de DOS (2) años para conservación de los datos cuando el deudor hubiere cancelado o extinguido la obligación, se tendrá en cuenta la fecha precisa en que se extingue la deuda".

Las reglas precitadas establecen en definitiva un plazo de caducidad del dato negativo, que implica "olvidar" por el mero transcurso del tiempo datos que reflejan hechos ciertos, lícitamente tratados e incluso subsistentes (porque puede que las deudas no hayan sido saldadas e igualmente los datos deban ser cancelados), tal como surge no sólo de la letra de la ley sino de la interpretación dada por la Corte Suprema argentina en los casos "Nápoli"13 y "Catania"14.

La extensión de este "derecho al olvido" a otros tipos de datosha generado gran polémica por cuanto los derechos y libertades que pueden oponerse a un derecho general a que ciertos hechos negativos sean olvidados luego de determinado tiempo pueden ser de mayor rango e incluso no serlo siempre y en todos los casos, ya que esa supremacía podría depender no sólo de las características particulares del caso sino también de los valores vigentes en una sociedad determinada y en un momento histórico concreto. Esto obliga a realizar una ponderación caso por caso para resolver la tensión entre el derecho colectivo a la información y los derechos individuales comprometidos por la publicación de esa información lesiva.

Existen diversos ámbitos donde se genera la mayor polémica sobre la aplicabilidad del derecho al olvido, por ejemplo, en el de la información judicial, pero en tal entorno es factible su aplicación, aunque limitada, a partir de las "Reglas de Heredia"15, que incluyen

13 CSJN, 8/11/2011, N.112, "Napoli, Carlos v. Citibank N.A. s/habeas data".

14 CSJN, 8/11/2011, C.1380 "Catania v. BCRA s/habeas data”.

15 “Reglas mínimas para la difusión de información judicial en Internet” aprobadas en Heredia, Costa Rica, en 2003 y disponibles en http://www.iijusticia. org/heredia/Reglas_de_Heredia.htm. 
principios característicos del derecho al olvido en las reglas 3 y $4^{16}$.

La cuestión se torna más conflictiva cuando el derecho al olvido se pretende utilizar con carácter general y en el marco de Internet, por el impacto que causa sobre principios estructurales, como el genérico a la libertad de expresión y el específico de neutralidad de la red.

Si bien la discusión teórica comenzó a tomar auge desde 2009 especialmente en el ámbito europeo a partir de propuestas que formulara VivianeReding (por entonces comisaria europea de protección de datos) a fin de empoderar a los internautas para protegerse de las amenazas de la red a través del reconocimiento de nuevos derechos (como el derecho al olvido y a la portabilidad de los datos), la cuestión ha sido abordada normativamente en el ámbito comunitario europeo desde 2012, cuando se pusiera bajo debate el proyecto de Reglamento General de Protección de Datos ${ }^{17}$.

Esta primera propuesta de Reglamento dedicaba diversas previsiones específicamente referidas al derecho al olvido tanto en los numerales 53 y 54 de su exposición de motivos como ensu extenso art. 17 ("Derecho al olvido y a la supresión”), pero tales reglas que fueron eliminadas en la versión de 2014 del proyecto para alojar -sin denominarlo así- el derecho al olvido dentro de los derechos tradicionales, especialmente en el de supresión, esto en momentos en los que, primeramente la Gran Salay luego el Pleno del Superior Tribunal de Justicia de la Unión Europea convalidaran la exigibilidad de un derecho al olvido en Internet en el leading case "Costeja"18.

Este caso se generó a partir una sanción aplicada por la Agencia Española de Protección de Datos a Google Spain y Google Inc. por la cual se ordenaba a Google la eliminación, en su buscador, de los enlaces respecto de la información personal vetusta obrante en la red que era obtenida a través del nombre del solicitante (se refería a un anuncio publicado en el diario "La Vanguardia" sobre un remate de un inmueble realizado varios años antes por unas deudas con la seguridad social), lo que implicaba que no se podía llegar a dicha noticia por su nombre (operación que doctrinariamente se conoce como "desindexación"), pero sí a través de otros criterios de búsqueda, por lo cual la información permanecía inalterada en la página original, pero sólo no podía ser accedida por el nombre del afectado.

La Gran Sala entendió que el derecho al olvido podía ser extraído conceptualmente delos arts. 12 y 14 de la Directiva 95/46/CE y por ello el gestor de un motor de búsqueda está obligado a eliminar los vínculos a las páginas web de la lista de resultados obtenida a partir del nombre de una persona, aunque la publicación sea en sí misma lícita, porque los derechos del titular de los datos prevalecen, en principio, no sólo sobre el interés económico del gestor del motor de búsqueda, sino también sobre el interés del público en acceder a la información por sunombre, aunque dicha solución podía diferir si la injerencia en los derechos fundamentales del titular de los datos estuviera justificada por el interés preponderante del público en tener acceso a la información de que se trate (por ejemplo, por el papel desempeñado por el interesado en la vida pública).

La decisión provocó que miles de ciudadanos europeos comenzaran a solicitar la desindexación de contenidos que los perjudicaban (para lo cual Google creó una comisión

\footnotetext{
16 La Regla 3, referida al derecho de oposición del interesado, indica que a éste se le reconocerá dicho derecho "previa petición y sin gastos, en cualquier momento y por razones legítimas propias de su situación particular, a que los datos que le conciernan sean objeto de difusión, salvo cuando la legislación nacional disponga otra cosa. En caso de determinarse, de oficio o a petición de parte, que datos de personas físicas o jurídicas son ilegítimamente siendo difundidos, deberá ser efectuada la exclusión o rectificación correspondiente", y la Regla 4, referida a la adecuación entre medios y fines, dispone que en cada caso "los motores de búsqueda se ajustarán al alcance y finalidades con que se difunde la información judicial".

17 Propuesta de Reglamento del Parlamento Europeo y del Consejo relativo a la protección de las personas físicas en lo que respecta al tratamiento de datos personales y a la libre circulación de estos datos (Reglamento general de protección de datos), 2012/0011 (COD), 25/01/12.

18 “Google Spain SL, Google Inc. v Agencia Española de Protección de Datos (es), Mario Costeja González”, Case n C-131/12, ECLI:EU:C:2014:317.
} 
especial y puso a disposición formularios para realizar y justificar los pedidos), generándose dificultades para resolver sobre la procedencia de las peticiones. Entre diversas iniciativas habidas al respecto, por ejemplo, el profesor MartSusi ha propuesto una fórmula matemática para realizar la ponderación de los derechos en juego a fin de que pueda decidirse de una manera estandarizada cuándo desindexar y cuándo no. ${ }^{19}$

Como consecuencia de la decisión adoptada por el Superior Tribunal de Justicia de la Unión Europea, y pese a la alta polémica que generó en cuanto a los alcances de su reconocimiento, el derecho al olvido finalmente fue mantenido en la versión final del Reglamento General de Protección de Datos (aprobada en abril de 2016 y aplicable desde mayo de 2018$)^{20}$, pero más allá de algunas referencias realizadas en la exposición de motivos de la norma, quedó relegado a su sola mención entre paréntesis en el epígrafe del extenso art. 17 referido al derecho de supresión.

En el ámbito interamericano, la Convención Americana sobre Derechos Humanos (OEA, 1969), debido alcontexto tecnológico existente al momento de su sanción, no incluyó normas sobre protección de datos,aunque refiere precisamente al derecho a la privacidad y al derecho a la libertad de expresión, que son los principalmente involucrados en el ámbito de Internet. Interpretando sus alcances, la Relatoría de la Libertad de Expresión de la $\mathrm{CIDH}$ ha sostenido que si bien un derecho general al olvido en Internet puede tener cabida en el ámbito europeo, las reglas sobre libertad de expresión vigentes en el sistema interamericano impedirían su aplicación ${ }^{21}$.

Sin perjuicio de lo expuesto, el derecho al olvido en Internet ha sido reconocido a nivel legal en el art. 10 de la ley 787 de Nicaragua de 2012, que establece el "derecho a ser olvidado digitalmente" en redes sociales, navegadores y servidores, y en el art. 11 del decreto 3755 de Costa Rica de 2012, que contempla la "derecho a ser olvidado" al establecer un plazo de vencimiento de 10 años a partir de la ocurrencia del evento relevante. Además, en aquellos países que no lo previeron expresamente, puede construirse mediante la aplicación conjunta de otras disposiciones, como los artículos 23 y 47.1 de la ley mexicana de Protección de Datos en Posesión de Sujetos Obligados de 2017 y mediante las previsiones del artículo 28.1. de los "Estándares de Protección de Datos Personales para los Estados Iberoamericanos" aprobados por la Red Iberoamericana de Protección de Datos (RIPD), que otorga al titular de los datos el derecho a oponerse al tratamiento cuando tenga "una razón legítima derivada de su situación particular".

Este derecho también ha sido reconocido por las decisiones administrativas de varios órganos de control de la región (por ejemplo, el INAI en México) y por decisiones judiciales que han reflejado diferentes puntos de vista en cuanto a la existencia y alcance del derecho. Así, por ejemplo: a) en Colombia, mediante la sentencia T-277 de 2015, la Corte

\footnotetext{
19 SUSI, Mart (2018): “The internet balancing formula" en "Revista Latinoamericana de Protección de Datos Personales”, n 5, diciembre de 2018, disponible en https://latam.lejister.com/articulos.php?Hash=c244b6530644be807dc60eeb8d073526\&hash_t=d0e4d49d4f8836f252a12153059179f1.

20 Reglamento (UE) 2016/679 del Parlamento Europeo y del Consejo, de 27 de abril de 2016 relativo a la protección de las personas físicas en lo que respecta al tratamiento de datos personales y a la libre circulación de estos datos y por el que se deroga la Directiva 95/46/CE (Reglamento general de protección de datos).

21 En este sentido, en los "Estándares para una Internet libre, abierta e incluyente", se ha sostenido: "132. Ahora bien, el derecho internacional de los derechos humanos no protege o reconoce el llamado "derecho al olvido", en los términos delineados por el TJUE en el caso Costeja. Por el contrario, la Relatoría Especial estima que la aplicación en las Américas de un sistema de remoción y desindexación privada de contenidos en línea con límites tan vagos y ambiguos resulta particularmente problemática a la luz del amplio margen normativo de protección de la libertad de expresión bajo el artículo 13 de la Convención Americana sobre Derechos Humanos.

"133. La remoción de contenidos en internet tiene un impacto evidente en el derecho a la libertad de expresión, tanto en su dimensión individual como social, y en el derecho de acceso a la información por parte del público. La información removida no circula, lo que afecta el derecho de las personas a expresarse y difundir sus opiniones e ideas y el derecho de la comunidad a recibir informaciones e ideas de toda índole. Un efecto similar, aunque no exactamente igual por su dimensión, es el que produce la desindexación de contenidos, en tanto los mismos se hacen más difíciles de encontrar y se invisibilizan. Ambos tienen un efecto limitador en la libertad de expresión en tanto restringen la posibilidad de buscar, recibir y difundir informaciones e ideas por parte de todas las personas, sin consideración de fronteras nacionales." (disponible en http://www.oas.org/es/cidh/expresion/docs/publicaciones/ internet_2016_esp.pdf).
} 
Constitucional ordenó que se actualizara la versión digital de un periódico para reflejar la exoneración del apelante y que los buscadores internos no permitieran el acceso externo a él; b) la Corte Suprema de Chile ordenó la eliminación de una historia en el portal digital de un periódico sobre un oficial de policía que había cometido un delito sexual hacía una década, y c) la Corte Suprema de Justicia de Brasil aplicó el derecho al olvido respecto de documentales televisivos referidos a actos criminales pasados en los casos "Curi" y "Chacina da Candelária", pero no extendió dicha doctrina a los buscadores de Internet al resolver el caso "Xuxa Meneguel".

\section{Conclusiones}

La cuestión referida a la existencia y extensión del derecho al olvido, en cualquiera de sus versiones, se encuentra en pleno debate tanto doctrinario, como legal y jurisprudencial y muy probablemente los diferentes puntos de vista acerca de su compatibilidad con la libertad de expresión no puedan arribar a una visión uniforme en pos de su reconocimiento.

Sin embargo, parece claro que ni una admisión sin limitaciones ni una negación absoluta son soluciones apropiadas y por ello debería ser reconocido universalmentepero de manera limitada y bajo una ponderación caso por caso donde sólo se lo reconozca respecto de informaciones que sobre las que no noexiste un interés público relevante que predomine sobre ese derecho a que sean expurgadas de la memoria colectiva.

En pos de su vigencia, parece oportuno extraer de la memoria colectiva las palabras que hace unos 130 años y frente a avances tecnológicos que amenazaban las libertades individuales, volcaran Warren y Brandeis:

"Que el individuo debería tener protección de su persona y sus propiedades es un principio tan antiguo como la ley, pero de vez en cuando es necesario definir de nuevo la naturaleza exacta y el alcance de esa protección. Los cambios políticos, sociales y económicos, suponen el reconocimiento de nuevos derechos, y la Ley, en su eterna juventud, debe crecer para satisfacer las nuevas demandas de la sociedad.

"Así, en los primeros tiempos, la Ley dio un remedio a la interferencia física con la vida y la propiedad. Más tarde se reconoció la naturaleza espiritual del hombre, de sus sentimientos y de su intelecto. Poco a poco el alcance de estos derechos se amplió y ahora el derecho a la vida se convirtió en el derecho a disfrutar de la vida -el derecho a ser dejado solo, a asegurar el ejercicio de los amplios privilegios civiles, y el término "propiedad" ha crecido hasta incluir toda forma de posesión, tanto tangible como intangible-. "Por lo tanto, con el reconocimiento del valor jurídico de las sensaciones, se amplió la protección contra lesiones físicas reales a la atención del temor de sufrirlas... más tarde llegó la protección frente a ruidos y olores ofensivos, contra el polvo y el humo, y la vibración excesiva... lo que se refiere a las emociones humanas pronto se extendió el alcance de la inmunidad personal más allá del cuerpo del individuo, a su reputación y el prestigio entre sus semejantes... se protegieron las relaciones familiares... similares a la expansión del derecho a la vida fue el crecimiento de la legal concepción de la propiedad. "De bienes corporales surgieron los derechos inmateriales que emiten fuera de él; y luego se abría el amplio ámbito de la propiedad inmaterial, en los productos y procesos de la mente, como obras de literatura y arte, secretos comerciales y marcas comerciales... "Este desarrollo de la ley era inevitable. La intensa vida intelectual y emocional, y la intensificación de las sensaciones que venía con el avance de la civilización, dejaron claro a los hombres que sólo una parte del dolor, el placer, y el beneficio de la vida yacía en las cosas físicas. 
"Pensamientos, emociones y sensaciones exigieron el reconocimiento legal, y la hermosa capacidad de crecimiento que caracteriza al derecho común permitieron a los jueces para proporcionar la protección necesaria, sin la interposición de la legislatura. Invenciones recientes y métodos comerciales llaman la atención sobre el siguiente paso que debe tomarse para la protección de la persona, y para asegurar que el individuo lo que el juez Cooley llama el derecho "a ser dejado solo".

"Fotografías instantáneas y periódicos han invadido el sagrado recinto de la vida privada y doméstica; y numerosos dispositivos mecánicos amenazan con hacer buena la predicción de que 'lo que se susurraba en el armario será proclamado desde los tejados'. "Durante años se ha producido una sensación de que la ley debe permitirse algún remedio para la circulación no autorizada de retratos de personas privadas y el mal de la invasión de la privacidad de los periódicos... la cuestión de si nuestra ley reconocerá y protegerá el derecho a la privacidad en este y en otros aspectos pronto deberá ser examinado en nuestros tribunales.

"De la conveniencia - de hecho de la necesidad- de alguna tal protección, no puede dudarse. La prensa está excediendo en todas las direcciones de los límites evidentes de la polémica y de la decencia. El chisme... se ha convertido en un comercio... Para satisfacer el gusto lascivo los detalles de las relaciones sexuales se extienden en las columnas de los diarios... columna tras columna se llena de chismes, que sólo pueden ser adquiridos mediante intrusión en el círculo doméstico.

"La intensidad y la complejidad de la vida, concomitantes con el avance de la civilización, han hecho necesario un poco de retiro del mundo, y el hombre, bajo la influencia refinadora de la cultura, se ha vuelto más sensible a la publicidad, por lo que la soledad y la privacidad se han vuelto más esenciales para el individuo; pero la empresa moderna y las invenciones, a través de invasiones sobre su vida privada, someten a un dolor y a una angustia mental mucho más grande que la que podría ser causada por las meras lesiones corporales...

"Es nuestro propósito de considerar si la ley vigente permite un principio que adecuadamente puede ser invocado para proteger la privacidad del individuo; y, si es así, cuál es la naturaleza y el alcance de dicha protección.

"Debido a la naturaleza de los instrumentos con los que la privacidad es invadida, la lesión infligida tiene un parecido superficial con los males tratados por la ley de la calumnia y la difamación...

"La ley común asegura a cada individuo el derecho de determinar, de ordinario, en qué medida sus pensamientos, sentimientos y emociones, se comunicarán a otros. En nuestro sistema de gobierno nunca puede ser obligado a expresarlas... incluso si ha elegido darles expresión, en general conserva la facultad de fijar los límites de su publicidad.

"La existencia de este derecho no depende del método particular de expresión adoptada. Es indiferente que sea por palabras o por signos, la pintura, la escultura o la música. Tampoco la existencia del derecho dependerá de la naturaleza o el valor del pensamiento o las emociones, ni del medio de expresión... En todos estos casos el individuo tiene derecho a decidir si lo que es suyo habrá de darse a publicidad..."22.

Los párrafos precedentes, donde claramente se imaginaba un nuevo remedio frente a los efectos perniciosos de los avances tecnológicos que finalmente resultó plenamente receptado en Occidente, resultan plenamente trasladables a análogas situaciones generadas en la actualidad en el ámbito de las TICs y por ello propiciamos el reconocimiento específico de este derecho, siempre sujeto a los límites que provienen del pleno ejercicio de las libertades informativas.

22 WARREN, Samuel - BRANDEIS, Louis (1890): “The Right to Privacy”, Harvard Law Review, vol. IV, núm. 5, 15/12/1890.págs. 194/220. 
BLIOGRAFÍA

- ARISTÓTELES (1995): Acerca de la memoria ("On memory"), en "The complete Works of Aristotle”, Jonathan Aristóteles Barnes (editor), Princeton University Press

- GHEZZI, Alessia (2014): Theethics of memory in a digital age, Palgrave Mac Millan, Reino Unido, 2014, cit. en O direitoaoesquecimento na Europa e no Brasil, en Revista de Derecho, Comunicaciones y Nuevas Tecnologías No. 15, Universidad de los Andes, Colombia, 2016, en prensa.

- MAYER SCHÖNBERGER, Viktor (2009): "Delete: the virtue of forgetting in the digital age", Princeton University Press

- PEYRANO, Guillermo (2004): "El tratamiento de datos personales extraídos de informaciones periodísticas, y su acceso a través de Internet. La protección de los datos personales y el derecho a la autodeterminación informativa, ante las nuevas formas de procesar y comunicar la información", en Estudios de Derecho - Estudios de Derecho Privado - Estudios de Derecho Público - Derecho Público y Procesal" (Homenaje a la Facultad de Derecho de la Universidad Católica Andrés Bello en su 50 aniversario), Editorial Universidad Católica Andrés Bello, Caracas (Venezuela).

- SUSI, Mart (2018): "The internet balancing formula" en "Revista Latinoamericana de Protección de Datos Personales", $n^{\circ} 5$, diciembre de 2018, disponible en https://latam. lejister.com/articulos.php?Hash=c244b6530644be807dc60eeb8d073526\&hash_t=dOe 4d49d4f8836f252a12153059179f1.

-WARREN, Samuel - BRANDEIS, Louis (1890): “The Right to Privacy”, Harvard Law Review, vol. IV, núm. 5, 15/12/1890. 